\title{
Cognitive Basis of Conceptual Borrowing
}

\author{
Larisa Gatsalova ${ }^{1}$, Tatyana Novikova, ${ }^{2, *}$, and Larisa Parsieva ${ }^{3}$ \\ ${ }^{1}$ North Ossetian State University, Vladikavkaz, Russia \\ ${ }^{2}$ Volgograd State University, Volgograd, Russia \\ ${ }^{3}$ North Ossetian Institute for Humanitarian and Social Research, Vladikavkaz Scientific Center of the RAS, Vladikavkaz, Russia
}

\begin{abstract}
The conceptual discrepancy of various linguistic and cultural systems sets the problem of transferring concepts when translating. A translator should borrow concepts of the source language to fill conceptual and cultural gaps of the target language. Abstract concepts based on metaphor represent the specific task of conceptual and cultural gap filling. Conceptual borrowing is one of the most complicated processes of translation practice and complex theoretical problems. The problem of conceptual borrowing could be solved with the help of cognitive models. The cognitive model of conceptual metaphor is the most productive one. Conceptual metaphor presents an image providing conceptual borrowing and cultural gap filling in order to achieve an adequate translation.
\end{abstract}

\section{Introduction}

Global information space of the modern world stipulates considerable efforts for interpreting phenomena of another culture. The anthropocentric paradigm of modern science allows linguacultural studies to become one of the leading interdisciplinary areas in discourse research.

New issues on discourse characteristics of recipients, their cultural background, linguacultural phenomena are studied to find the productive way of ensuring intercultural communication and translation and creating new person-oriented techniques of interpreting cultural information.

\section{Background}

Developing humanitarian knowledge has put forward a problem of working out a term that would adequately present cognitive units and merge psychological and linguistic categories. Nowadays, the term which is clear to all professionals in the sphere of cognitive and linguacultural research is concept.

Though each researcher provides his/her understanding of the umbrella term, the basic meaning remains the same. Most researchers treat concept as a cognitive, psycholinguistic, linguacultural phenomenon and define it as a multi-dimensional cluster of sense or a quantum of knowledge.

Today, the term concept is widely used in cognitive linguistics, cultural linguistics and translatology. Borrowing concepts is necessary in the practice of translation. The problem of conceptual borrowing is solved with the help of comparison of cognitive models in the source language and in the target one.

\section{Literature review}

In Russian linguistics, the term concept is not monosemous. According to Likhachev, Stepanov, Lyapin and others, concept is understood as a unit of the collective consciousness, "bunch of culture", which is stored in the memory of native speakers in verbally determinate form.

Culture enters the mentality in the form of a concept like an abstract, an idea or a symbol, and people affect the culture through the concept. The concept is a discrete unit; it includes understandings, evaluations, likes and dislikes, emotions of people. Concepts are experienced and cognized by them.

Concept as a cognitive term is also defined as a "unit of knowledge" but most researchers presume concepts to have cultural sense besides linguistic meaning. Only those phenomena of reality and culture can become concepts that are relevant to and valuable for native speakers of a particular language.

The concept is a mental structure representing the knowledge of both the individual person and the entire linguistic community about a particular phenomenon. Being a part of the world picture, the concept reflects the values orientation through proverbs and sayings, poetry and prose texts.

It is these texts that give the understanding of a particular cultural situation, and with the help of them the concept can be identified, i.e. concepts describe typical situations of culture and that is why they become the subject of studies in cultural linguistics and translatology.

Researchers of different countries treat the concept as a cognitive or psycholinguistic or linguacultural phenomenon. Every scientific approach highlights the 
specific features of the concept according to scientific purposes stipulated. One of them shows the bonds between language and culture, too.

Anna Wierzbicka [1] states that the concept is an object of the "ideal" world. It has the name and reflects people's cultural understanding of the real world. According to the cognitive scientific tradition, the concept is related to the verbal means of expression of its sense, its cognitive content.

Language does not form concepts entirely, but serves as a means of exchanging cognitive information in the process of communication. Concepts are fixed in the meaning of a linguistic sign. Various concepts can be expressed with a word, a phrase, and even a text revealing some image.

Analyzed as a cognitive phenomenon, a concept is presumed to include information which an individual knows, suggests, thinks, and imagines about some object. From the point of view of cultural linguistics, a concept reflects the result of the linguistic community's experience, of all human activities.

Concepts exist in the mentality of an individual and are verbalized in communication with words, phrases and entire texts. Mental and verbal representations of the concept are interconnected. The understanding of a concept is the result of the categorization of knowledge in the collective consciousness.

Karasik [2] proposes considering the cultural concept as a multidimensional meaningful construct with notional, imagery and value elements being distinguished. The core of the concept is formed with associations which are most relevant to native speakers, while less significant ones constitute the periphery.

The notional aspect of a concept is its definition in relation to other concepts. The imagery aspect of a concept is visual characteristics of an object reflected in the consciousness. The value aspect of a concept specifies its importance for an individual and the linguistic community, its evaluative characteristics.

The concept is considered to be a self-organizing, functional mental unit with the evaluative element dominating. The concept manifests itself in the speech with the help of language units which not only describe the object but also create its conceptual equivalent in a person's mind.

So it is obvious that the study of linguistic and cultural concepts is one of the most important research trends in linguistics in recent years but the problem of borrowing concepts is not less significant. It is relevant to the task of gap filling while translating in order to achieve an adequate translation.

Researchers suppose conceptual borrowing to be quite possible between two languages under certain conditions: "Any concept or fusion of concepts is borrowable from a donor language if it conforms to the semantic possibilities of the recipient language with regard to conceptual types...» [3].

Most scholars stress the importance of bilingualism as one of the main factors of borrowing: «... in order to explain the widespread use of loanwords for new concepts, one probably needs to appeal to the convenience of using the loanword in situations of reasonably widespread bilingualism» [4].

The cultural aspect of the process of borrowing is also underlined in many investigations concerning loan words: «Borrowing of new words along with new concepts (cultural borrowing) and borrowing for reasons of prestige (core borrowing) are the two most important reasons for borrowing» [5].

\section{Conceptual borrowing}

The structure of concepts is not rigid; this is the ultimate principle of their existence in the individual and collective consciousness, developing their mental characteristics and their entry into the conceptual corpus of an individual person and the conceptual totality of a certain culture.

Due to its mental characteristics a concept provides understanding a phenomenon of reality. According to Evans, internal structure of the concept includes a sensual image, informational content and interpretative field. The structure of the concept is formed by cognitive features, which vary in the degree of brightness [6].

The sensual image in the structure of the concept is formed by perceptual cognitive features reflecting the environment through the organs of perception in the native speaker's mind. But being once fixed in language units, they stop being contingent on the sensual perception.

That is why people who have never seen some phenomenon could imagine it while reading or listening to its description. Phenomena of another cultural reality may be available through the translated text only, but they could be cognized with the help of their description in the text.

The informational content of the concept consists of cognitive features which determine the distinguishing characteristics of a phenomenon. But while scientists try to create the most distinct definition of some object, other people just describe it making no attempts to define it consistently.

So there is the interpretative field of a concept which includes not only informative cognitive features but also figurative ones. They are necessary for the metaphorical interpretation of the informational content of the concept. Figurative features make understanding phenomena easier.

A translator is accountable for the right interpretation of a concept of another culture in the situation of crosscultural communication. Besides, particular responsibility consists in the correlation of concepts of different cultures in the process of professional translation.

Translation is a kind of cultural transfer. In order to transfer a concept, a translator should analyze its structure, correlate sensual images, informational content and interpretative fields of similar concepts in two cultures and choose units of the target language to achieve an adequate translation.

The structure of a concept can be revealed only when its elements are represented in the process of speech and 
fixed in the system of a language. The core of the concept can be named with a word or phrase, the periphery including cultural traditions and personal experience is revealed in the text.

The notional element of a concept is usually represented in the vocabulary definition but imagery and value elements can be revealed through the speech, with the help of an oral or written text, the author of which is a native speaker or a bilingual, a bearer of cultural information.

Cultural concepts differ from other mental units; they are notable for value components which can be interpreted on the basis of corpus of texts in a certain language. The system of cultural concepts reflects the system of values existing in the linguistic and cultural community.

Abstract concepts [7] are mental units which express comlex cognitive senses of existence discourse [8] and have a great axiological value. The concepts are often based on metphor and offer difficulty of transfer and conceptual gap filling in the process of professional translation.

A person's subjective actualization of a cultural concept in his/her speech may serve not only as a means of presenting some cognitive content but also as a means of creating new conceptual sense as the result of the activities in the situation of cross-cultural communication.

Successful communication is only possible when systems of concepts belonging to the participants of the communication coincide to a great extent; or if one of the participants is ready to borrow some concepts, i.e. some elements of the conceptual system of another culture.

In case conceptual systems do not coincide, the task of translation consists in determining the optimal means of filling the conceptual gap in order to achieve an adequate translation. It is necessary to choose a proper equivalent for the name of the concept of another culture to decide an issue.

Translation represents a cognitive process of semiotic interaction between an interpreter and a sign being interpreted which takes place in the translator's mind and is aimed at revealing the concept to eliminate possible discrepancy of the sender's intention and the recipient's interpretation.

Translating the names of concepts with the help of calking is not very rare. Calking some words was the way for the supplement of the conceptual system of Russian culture with the following concepts: kachestvo zhizni (life quality), politkorrektnost' (political correctness), global'nye vyzovy (global challenges).

The names of the concepts tolerantnost' (tolerance) and privatnost' (privacy) were borrowed with the help of morphological calking. In this case a foreign word is transliterated partially and provided with the suffix belonging to the language which borrows a word as the name of a new concept.

In such cases a newly borrowed concept is created on the basis of the meaning of the word acting as the name of the concept and the information obtained from texts which include the name of the concept and reveal its content; then it begins its own cognitive life in the mental space of the borrowing culture.

Over the period, the concept is enriched with additional cognitive features, deepen and widen its structure, and little by little it is integrated into the conceptual system of the borrowing culture. Moreover, it starts forming associative relations with some native concepts.

So the name of a newly borrowed concept starts being associated with some elements of the information space (persons, texts, etc) and gradually becomes a full member of some concept cluster within the frame of the conceptual system of the language once having borrowed the word.

The name of a cultural concept often represents a culture-specific word, i.e. a word having no direct equivalents in other languages (e.g., $a в о c b$, интеллигенция, соборность). Such words are borrowed with the help of transcription or transliteration because of their unique conceptual content.

However, national originality and cultural peculiarities of these concepts along with many others (духовность, непротивление, пошлость, порядочность, смекалка, разговор по душам, выяснение отношений, etc) remain unrevealed and could be clarified through the text only.

As a rule, the necessity of the manifestation for a concept of another culture while translating the text stimulates inevitably the borrowing of the concept name and filling the cultural gap through describing the unfamiliar conceptual phenomenon in the text of translation.

Descriptive translation and translator's remarks are the most widespread ways of translation when the conceptual system of the target language lacks some concept. The text of translation allows to interpret the basic informative content of a concept borrowed and even learn something about its cultural value.

Russian culture lacks the abstract concept sabi, for example. The core of this Japanese concept can be expressed as graceful simplicity but the structure of the mental unit includes more than one sense, it covers the whole aesthetic outlook embracing a lot of cognitive elements.

So depending on the original context, it could be manifested in the text of translation as an object concept a piece of art implementing the old spirit of harmony or as a script concept silence in solitude in the countryside accompanied with listeningto a single sound. The choice is a translator's task.

Facing such cultural phenomenon of another cognitive reality, a translator let the unfamiliar cultural experience through his/her mind in order to create a concept on the basis of associative relations of his/her own system of concepts and his/her own bilingual experience.

Then, the translator fills the conceptual gap being the result of the discrepancy of cultural experience and two linguistic systems. He/she borrowes the lexical unit which serves as the name of the concept and gives the descriptive translation presenting his/her interpretation of the concept. 
Making the translation, he/she uses as basis the linguistic and cultural context, his/her cultural background and surely inserts the remark concerning the national and cultural origin of the unfamiliar concept in the text of translation for a recipient to be able to interpret it.

A recipient's interpretation of the concept description depends on his/her own linguacultural competence and some personal characteristics. The recipient obtains the information about the concept of another culture from the text of translation and the result of interpretation becomes more familiar for him/her.

While reading or listening to the text of translation, he/she brings the new concept into correlation with elements of his/her own conceptual system, and the concept name used more than once in the text promote the fixation of the concept borrowed from another culture in mind.

Abstract concepts which are structurally based on metaphor represent the specific task of the correlation of cognitive models in the source language and in the target one. Stable correlations of the metaphorical transfer fixed by European cultural tradition allow to use the origin spelling of the concept name.

Most European languages use the following names of German and French abstract concepts created on the basis of metaphor: Walpurgisnacht, Hintergrund, coup de grâce, droit de seigneur, eclat, elan, tour d'ivoire, etc. So they are already borrowed as mental units along with their names and cultural traditions.

Abstract concepts of another culture which are metaphorically structured are integrated into the concept system quite easily if they are based on the cognitive models similar to those of the borrowing culture and manifested with the help of the text which is interpreted easily, too.

Metaphor correlates by analogy some abstraction with sense data and is a widespread mechanism of creating abstract meaning. Speech experience usually fix mental representations based on the intuitive sense of likeness between abstract and concrete phenomena of reality.

Metaphorical thinking is intensive because it allows to compare two objects which are incomparable from the logical point of view. Logical thinking forms the cognitive notion while the modeling activity of the metaphor consists in creating the cognitive image of a real phenomenon.

The experience of the linguistic and cultural community predetermines peculiarities of the metaphorical transfer as for both the choice of cognitive structures interacting in the process of the metaphorical transfer and the choice of characteristics being tranferred.

A cultural concept created on the basis of the metaphorical transfer possesses a great heuristic power due to its scope of both rational and irrational connections, and this is the reason for borrowing such a concept as a component of linguistic and cultural experience [9].

Metaphor is often studied as a means of figurative representation of reality and a stylistic means but less often as a productive cognitive model. When creating a specific image of an abstract concept, metaphor allows to borrow the notional, imagery and value elements of the concept altogether.

Concept is explained by metaphor as a figure of speech with the help of other concepts. Metaphor takes a concept out of its regular usage and places it into another position to which it is related to provide a new view of it to learn its characteristics which were not revealed before.

These unusual characteristics of the phenomenon presented generate the emergence of conceptual gaps. A translator should never disregard the gaps, especially in respect of the existence discourse which is rich in complex concepts presenting philosophical or psycological phenomena, for example.

The names of such concepts can be inserted into the source text in their origin spelling or as calques and they can be not explained in any way. In this case a translator could manifest the concept in the target text through translator's remarks. This would compensate eventual losses of meaning to some extent.

Abstract concepts borrowed from another culture can be interpreted by the recipient with variations because of the ambiguity of referent, alien conceptual structure and great associative potential. The minimum content of the meaning for the concept name is usually fixed in the dictionary of foreign words.

The cultural information connected to the concept can be revealed only in the text which belongs to the donor culture or to the borrowing one. A recipient's interpreting the context presents processing the information within the scope of his/her cognitive structures.

The quality of interpreting the concept borrowed depends not only on the grade of the linguacultural competence but also on the motivation to obtain some new information about another culture, to compare two cultures, to try something new in one's own language, and to attempt to influence another language.

«Speakers of different languages can often be found to differ in patterns of language use that are related to processes of categorization and conceptualization, and they likewise show that such patterns acquired through one language often carry over into the use of another language» [10].

The efficiency of borrowing also depends on how much a concept of another culture is unfamiliar, the availability of similar concepts in the borrowing culture, and the grade of the content or structure complexity of a concept, the presence of metaphorical base and object or script element in the structure of a concept.

\section{Conclusion}

Language is used not only to form a concept but also to exchange concepts in the process of cross-cultural communication. Concepts exist in the mentality of people and are verbalized with separate words, phrases, or the whole texts depending on the characteristics of a concept. 
The notional component of a concept is stored in mind in a verbal form and can be described and interpreted. The choice of language units depends on the factors of personal mental representation of a concept and the person's word stock which are important to reveal imagery and value components.

The analysis revealed that the conceptual discrepancy of linguistic and cultural systems make a translator borrow concepts of the source language to fill conceptual and cultural gaps of the target language in order to achieve an adequate translation of a text which is culturally-loaded.

To manifest some complex cognitive sense of existence discourse, it is often necessary for a translator to borrow an abstract concept and fill the conceptual or cultural gap. Abstract concepts based on metaphorical transfer provide productive cognitive models for borrowing.

Besides, conceptual metaphor presents an image providing efficient conceptual borrowing and interpreting the concept borrowed by native speakers of the borrowing language in a wide scale of its specific cognitive characteristics and peculiarities of its figurative verbal form.

The reported study was funded by RFBR according to the research project \#18-012-00440 "Active processes in vocabulary of multi-structural languages: internal development and external interaction"

\section{References}

1. A. Wierzbicka, The Case for Surface Case. (Arbor, 1980)

2. V.I. Karasik, Peremena, 3-16 (2001)

3. F. Field, Linguistic Borrowing in Bilingual Contexts. (John Benjamin's Publishing, 2002)

4. M. Haspelmath, Lexical borrowing: concepts and issues. Loanwords in the world's language. (2009). Available

from: https://www.researchgate.net/publication/27997391 6_Lexical_borrowing_concepts_and_issues [accessed May 19 2018]

5. Ibid. P. 50

6. V. Evans, How Words Mean (OUP, 2009)

7. T.B. Novikova, Borrowing cultural concepts (Peremena, 2005)

8. V.I. Karasik, Peremena, 33-34 (2000)

9. T.B. Novikova, Peremena 20 (2005)

10. S. Jarvis, Conceptual transfer: Crosslinguistic effects in categorization and construal. (2011). Available from: https://www.researchgate.net/publication/23186905 1_Conceptual_transfer_Crosslinguistic_effects_in_c ategorization and construal [accessed May 21 2018] 